\title{
Recruiting on the Net: insights for employers from prospective employees
}

\author{
Md Sohel Chowdhury
Graduate School of Business Administration, Inha University, \\ Md Sohel Chowdhury
Graduate School of Business Administration, Inha University, \\ Incheon, Republic of Korea and \\ Department of Management Studies, University of Barishal, Barishal, Bangladesh
}

Received 23 September 2021 Revised 6 December 2021 Accepted 29 December 2021

\begin{abstract}
Purpose - Drawing on the signaling theory and technology acceptance model, the main purpose of this study was to predict prospective employees' intentions to apply for jobs in a firm, with a special focus on the mediating role of attitudes toward corporate websites and the moderating role of perceived value fit.

Design/methodology/approach - Collecting data from a convenient sample of 318 prospective job candidates, the research hypotheses were tested using structural equation modeling (SEM) with AMOS (version 24) and SPSS Process Macro (version 3.4).

Findings - The test results revealed that prospective employees' attitudes toward corporate websites partially mediate the association of corporate reputations, perceived ease of use and perceived usefulness with their intentions to apply for jobs in an organization. Noticeably, perceived value fit moderated the perceived usefulness-application intentions link in such a way that the impact of perceived usefulness on intentions to apply appears higher for individuals with a low level (than a high level) of perceived value fit.

Research limitations/implications - Consistent with the research findings, a notable theoretical contribution and practical implications for HR professionals have been discussed. This paper ends with outlining some limitations and future research directions.

Originality/value - Despite having the salient buffering effects of perceived value fit on the applicant attraction process, empirical study on this theoretical phenomenon is still sparse in a pre-employment context. This may be the first study that demonstrates under what circumstances prospective employees' job pursuit intentions could be optimized in respect of their perceived value fit within a single framework comprised of two theories.
\end{abstract}

Keywords Bangladesh, Corporate reputation, Prospective employees, Signaling theory, Technology acceptance model, Value fit

Paper type Research paper

\section{Introduction}

What is the major challenge for a human resource $(\mathrm{HR})$ manager? It is undeniable that demographic and economic changes over the last couple of years have led the organizations to fierce competition for attracting qualified candidates (Uggerslev et al., 2012). Social scientists argue that attracting the right people at the right time is getting harder than ever. In line with this, many researchers noted that attracting high-quality candidates is one of the

(C) Md Sohel Chowdhury. Published in PSU Research Review. Published by Emerald Publishing Limited. This article is published under the Creative Commons Attribution (CC BY 4.0) licence. Anyone may reproduce, distribute, translate and create derivative works of this article (for both commercial and noncommercial purposes), subject to full attribution to the original publication and authors. The full terms of this licence may be seen at http://creativecommons.org/licences/by/4.0/legalcode.

Originality -This manuscript is an original work and has not been published, or submitted for publication elsewhere.

Data availability - The SPSS dataset used in this study is available on reasonable request.

Conflict of interest - There is no relevant financial or non-financial interests to disclose.

Funding - This research received no external funding.

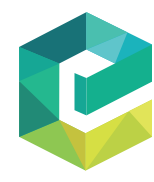

PSU Research Review Emerald Publishing Limited 2399-1747 
key tasks for an HR manager of an organization (e.g. Banerjee and Gupta, 2019; Chowdhury et al., 2021). If a firm fails to attract talented potentials properly, it may result in organizational failure in the long run, as demonstrated by Ehrhart et al. (2012). Because of its immense importance, researchers urged $\mathrm{HR}$ managers to boost their firm attractiveness by influencing potential applicants' job pursuit intentions.

Today's firms use various forms of communication to enhance their attractiveness to prospective employees. It is through recruiting that a company may find and attract potential individuals for job openings. It is a time when an employer can develop an early employment relationship with potential applicants who can learn more about the organization and job information to make a decision on whether to apply to the organization or not. Though there are various sources of recruitment, in this digital era, traditional recruitment efforts have been replaced by web-based recruitment (Banerjee and Gupta, 2019). In this respect, a substantial body of research has examined the role of potential antecedents in predicting applicants' intentions to apply for jobs in a firm (Chowdhury and Kang, 2021).

To the best of our knowledge, the extant recruitment research in this field mainly focused on the various features of the website itself, such as design and content information (e.g. Pfieffelmann et al., 2010), while some other recruitment researchers investigated a series of constructs which are not directly related to website features, such as social pressures (e.g. Griepentrog et al., 2012), person-organization fit (e.g. Chowdhury et al., 2021), and so on. Furthermore, most studies in this field are largely centered on Western societies; empirical research explicitly focusing on a developing country context is very limited. Therefore, researchers are still keen to develop a comprehensive model for predicting job seekers' attraction to an organization (Waples and Brachle, 2020).

To address these research gaps, this study proposes a theoretical framework to examine the underlying mediating mechanisms and boundary conditions of application intentions of potential candidates for an organization. More specifically, this research aims to combine signaling theory and the technological acceptance model into a single framework to examine the relationship between the psychological variables and determine the role of a moderating variable that seemed to be salient in the suggested relationships. That is, this study incorporates corporate reputation, perceived ease of use and perceived usefulness as independent variables; intentions to apply as the ultimate dependent variable; attitudes toward website and perceived value fit as mediating and moderating variables respectively.

Therefore, this study is expected to complement the existing body of knowledge in the related literature and provide some valuable insights for HR managers in today's competing organizations. In line with the main purpose of the study, a series of hypotheses were developed based on the predicted relationship among the constructs presented in the hypothesized research model (shown in Figure 1). The majority of the hypothesized relationships among the constructs were drawn from the applications of the signaling theory and the technology acceptance model (TAM), while some others were based on the findings reported by the prior studies in this field.

\section{Theoretical background and hypotheses development \\ 2.1 Signaling theory}

Signaling theory (Spence, 1973) posits that very often individuals need to make decisions about certain behaviors based on the information available at hand. In this situation, individuals use the available information as cues and draw inferences to take the final decision. In line with the importance of signaling theory in recruitment literature, Tsai et al. (2015) noted that signaling theory has the potential to determine the predictors of job seekers' intentions to apply for jobs in an organization. In fact, in the recruitment context, the signaling theory suggests that job seekers very often have limited information about the 


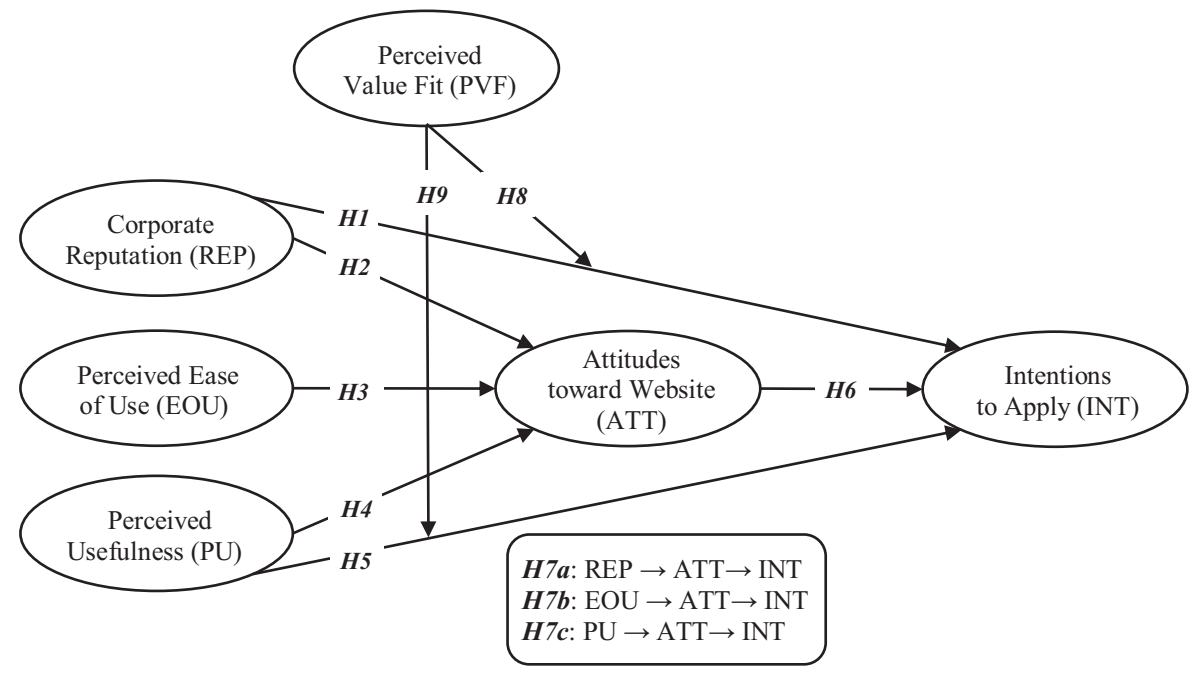

Recruiting on the net

desired job and the organizational attributes; however, they must base their decisions on the available information and knowledge while applying for a job.

2.1.1 Corporate reputation and application intentions. Reputation is an intangible asset for any organization and has been reported to be influential for talent acquisition in past studies (Story et al, 2016). The corporate reputation of a firm consists of job seekers' beliefs or perceptions about how the firm is viewed and evaluated by the general public, not by the job seekers themselves (Cable and Turban, 2001). They further noted that potential applicants may use a company's reputations as signals to infer the working conditions of the organization in which they are pursuing jobs. Applying this line of reasoning, prior studies demonstrated a significant influence of job seekers' corporate reputation perceptions on their application intentions (Chaudhary, 2018; Yeum and Han, 2014). Based on the above discussion and findings of the past studies, the following hypothesis was drawn:

H1. Corporate reputation is positively related to job seekers' intentions to apply.

2.1.2 Corporate reputation and attitudes toward website. There is no consensus about the definition of corporate reputation (Zhang et al., 2020). Some researchers defined reputation from a cognitive perspective, while others termed it as an affective component. As noted earlier, corporate reputation in this study was defined as an individual's belief and the evaluative aspects of those beliefs (Fishbein and Ajzen, 1975). As job seekers have limited information about a potential recruiting firm, they consider the firm's reputation status as a clue to take their career-related decisions. Melo and Garrido-Morgado (2012) noted that job seekers' beliefs about a firm's reputation status can be a key source for its competitive advantage over other firms to attract a talented pool of candidates, implying its positive association with their attitudes toward the corporate website. On these premises, the following hypothesis was devised:

H2. Corporate reputation is positively related to attitudes toward corporate website.

\subsection{TAM}

Davis (1989) firstly introduced the TAM in human-computer literature as a combination of the theory of reasoned action and the theory of planned behavior. According to the TAM, an 
individual's decision to accept or reject a new technology entirely depends on five constructs: external variables, perceived ease of use, perceived usefulness, attitudes toward technology and behavioral intentions to use (Ahmad et al., 2017; Safari et al., 2020). Applications of TAM in the prior recruitment literature give us insights into the effectiveness of this model. Therefore, in the present study, this theoretical notion was applied to examine job seekers' application intentions. In this study, constructs such as "attitudes toward technology" and "intentions to use the system" were demonstrated as "attitudes toward corporate websites" and "intentions to apply for jobs in an organization", respectively.

2.2.1 Perceived ease of use, perceived usefulness and attitudes toward website. According to Davis (1989), while perceived ease of use refers to the extent to which a user can easily utilize a new technology or system with less effort, perceived usefulness refers to the effectiveness of the system that adds value to the performance of a user. The attitudes refer to a person's emotional state about a particular object or action. In a competitive business arena, an organization needs to design its recruitment website in such a way that it will not hinder potential users from using the system. If the job seekers find the website difficult in navigating different locations and searching required information, it will have a significant impact on users' attitudes toward the website (Gregory et al., 2013). Furthermore, to be useful, corporate recruitment websites need to include the necessary organizational and job-related information so that it can influence applicants' attraction to the hiring organization. If a job seeker finds the website easy to use, he or she will be motivated to use it further and can find the related job and organizational information if it is available in the system. Consequently, the following two hypotheses were developed:

H3. Perceived ease of use is positively related to attitudes toward corporate website.

H4. Perceived usefulness is positively related to attitudes toward corporate website.

2.2.2 Perceived usefulness and application intentions. Past studies in this field convincingly reported that the usefulness of a corporate website for communicating employment information is a key antecedent of an organization's ability to influence potential applicants' intentions to apply for the job vacancies offered by the organization. Drawing on the TAM, Hossain et al. (2019a, b) in their study also stated that individuals' perceived usefulness is likely to have significant influence on their behavioral intentions. In addition, marketing literature posits that consumers' perceptions about the usefulness of a product influence their intentions to buy the product. If the marketing literature is applied to the recruitment context, it is plausible to expect that job seekers' perceived usefulness of the corporate recruitment website influence their intentions to apply for the job offered by the hiring organization. On the basis of these grounds, the following hypothesis was formulated:

H5. Perceived usefulness is positively related to job seekers' intentions to apply.

2.2.3 Attitudes toward website and application intentions. A substantial body of research in this field demonstrated attitudes as cognitive constructs, defined as a person's beliefs or cognitions toward an object and intentions as affective constructs, defined as a person's affective association with a particular object or action. Consistent with many past studies, attitudes and intentions are considered as cognitive and affective constructs respectively in the present study. Given the fact that cognitive notions may have a substantial impact on emotional constructs (Fishbein et al., 2003), it is also reasonable to expect that job seekers' attitudes toward corporate websites are likely to influence their intentions to apply for jobs in an organization. Consequently, the following hypothesis was predicted:

H6. Attitudes toward corporate website are positively related to intentions to apply. 


\subsection{The mediating roles of attitudes toward website}

The theoretical arguments for this paper so far suggest that corporate reputations, perceived ease of use and perceived usefulness are associated with attitudes toward corporate websites, which in turn lead to intentions to apply for jobs. Hence, it is meaningful to check the indirect effects of those independent variables (i.e. corporate reputations, perceived ease of use and perceived usefulness) on the ultimate dependent variables (i.e. intentions to apply for jobs) through the influence of the mediator in this study (i.e. attitudes toward websites) (Shin et al., 2016). Another rationale for testing the mediating effects of attitudes toward websites was based on the notion that if $\mathrm{A}$ affects $\mathrm{B}$, and $\mathrm{B}$ affects $\mathrm{C}$, then the impact of $\mathrm{A}$ on $\mathrm{C}$ through the influence of B should be significant (Chowdhury and Kang, 2021). Based on these arguments, the following mediating hypothesis was formulated:

H7. Attitudes toward websites mediate the relationship between (a) corporate reputations, (b) perceived ease of use and (c) perceived usefulness and intentions to apply.

\subsection{Perceived value fit}

Perceived value fit refers to an individual judgment about the compatibility between personal characteristics and organizational characteristics (Gregory et al., 2013). It may be objective or subjective. Dineen et al. (2002) defined objective value fit as "an individual's actual or measured values being congruent with an organization". Objective value fit influences the post-hiring performance of existing employees, such as organizational commitment, job performance, job satisfaction, or turnover intentions. Subjective value, on the other hand, relates to the degree to which individuals consider themselves to be compatible with organizational characteristics, i.e. shared values, culture, beliefs and ideologies, prior to entry into the organization (Gregory et al., 2013). In the present study, job seekers' perceived value fit was used as a moderating variable as it appeared to be influential in the suggested relationships in the research model.

2.4.1 The moderating roles of perceived value fit. The elaboration likelihood model (ELM) (Massaro et al., 1988) suggests that if prospective candidates, viewing recruitment websites, perceive that the available information regarding organizational characteristics is compatible with their personal characteristics (i.e. higher value fit), then they form a favorable attitudes toward the organization. In contrast, if the candidates find irrelevant information (i.e. lower value fit) on a website, they would be less motivated to explore more specific content and may form an opinion based on "peripheral" cues, such as corporate reputations. Consistent with the ELM, past studies have demonstrated that if the perceived value fit is high, prospective candidates value organizational information more than their perceptions of corporate reputations, and thereby the impact of organizational information on applicant attraction is higher than that of corporate reputation. Applying this line of reasoning, the present study also hypothesized the following:

H8. Perceived value fit moderates the relationship between corporate reputation and intentions to apply, such that the relationship would be stronger when the perceived value fit was lower and vice versa.

In addition, past studies (e.g. Bednarska, 2016; Pfieffelmann et al., 2010) have demonstrated that job seekers are more interested in pursuing jobs in an organization that is congruent with their personal norms (i.e. perceived value fit). Personal norms refer to the internal standards concerning a particular action (Kallgren et al., 2000). This study argued that personal norms are more critical for millennials since they are individualistic and excessively focused on their own demands (Twenge, 2009). Given that the perceived usefulness of the website may allow potential applicants to examine whether their personal values and norms fit well with those of
Recruiting on the net

$+$


the organization (Gregory et al., 2013), it is plausible that the impact of perceived usefulness on application intentions will be lower when the millennial job seekers' perceived value fit is higher. Based on these premises, the following hypothesis was developed:

H9. Perceived value fit moderates the relationship between perceived website usefulness and intentions to apply, such that the relationship will be stronger when the perceived value fit is lower and vice versa.

\section{Research method}

\subsection{Sample and procedure}

In line with the objectives of the study, a person-administered questionnaire was devised to collect data from final-year undergraduate and graduate students enrolled in two public universities (i.e. University of Barishal, Patuakhali Science and Technology University) of the country. It is worth mentioning here that the target participants of the study were an appropriate sample as most firms in the country consider final-year students as their future human resources (Chowdhury and Kang, 2021). Furthermore, these students are likely to suffer career difficulties soon following their graduation, and hence, they are very aware of the job market and potential hiring firms.

To check the understandability of the questionnaire items, a pilot study with a convenient sample of 20 respondents was performed. The test results revealed no significant concern for the items, indicating that the items were comprehensible for the study participants. After performing the pilot test, an online link to the formal survey questionnaire was sent to the respective class coordinators, requesting them to forward the link to the class students to fill in the survey form. Respondents were assured about the anonymity of their identification and responses. At the beginning of the form, participants were first asked to recall a firm website that they most recently visited for job-seeking purposes, and then to answer the survey items.

A total of 342 participants submitted the form, out of which 24 respondents seemed to be unengaged while filling in the survey questionnaire as the standard deviations of their answers were found to be zero. Hence, in order to prevent misleading results, their observations were excluded from further analysis for this study. The remaining sample size (i.e. $n=318$ ) is ideal for the focal six variables of the present study (Hair et al., 2009). There was no missing value in the dataset as all the responses to the items were set mandatory requirements to submit the form successfully. The demographics of the respondents are as follows: $62.6 \%$ were male, $51.6 \%$ were between the ages of 21 and 23 , and $72 \%$ were final-year undergraduate students.

\subsection{Measures}

The measurement instruments for each variable of the study were chosen based on the past studies that were demonstrated as reliable and valid. Items were measured using five-point Likert-type scales ranging from strongly disagree (1) to strongly agree (5). The study constructs were calculated as the mean value of all the items of the respective construct. A higher score indicates a higher level of a construct. Some items were tailored to fit into the study context. A brief overview of the measurement items is as follows:

3.2.1 Corporate reputation. This construct assessed the degree to which the respondents perceived that the firm they visited on the net is well-reputed in society. The 5 items of firm reputation were adapted from Highhouse et al. (2003). A sample item of organizational reputation was: "I have heard a lot of good things about the organization". The reliability estimate for this construct was 0.813 . 
3.2.2 Perceived value fit. This construct assessed the respondents' perceptions about the compatibility between their values and those of the firm. This was measured with six items adapted from Cable and DeRue (2002), and Saks and Ashforth (1997). A sample item was "I feel that the firm will enable me to do the kind of work what I want to do". The internal consistency estimate for this construct was 0.820 .

3.2.3 Perceived ease of use. This construct, measured with four items, examined the respondents' self-confidence and ability to visit the corporate website properly. The items were adapted from Cober et al. (2003). A representative item used was: "It seems that the use of the corporate website is easy for me". The internal consistency found in the study data was 0.726 .

3.2.4 Perceived usefulness. It measured the degree to which a person thinks that browsing the company website is useful for finding information related to jobs and the company. Five items were taken from Palmer (2002). One of the items included was: "The company website provides all the related information that I want". The Cronbach alpha of this construct was 0.779 .

3.2.5 Attitudes toward corporate website. Through this construct, individuals' emotional states about the company website were weighed with 4 items adapted from Lin (2010). A sample item of website attitudes was: "Using the firm website to find the job information is a good idea". The reliability coefficient of this variable was 0.813 .

3.2.6 Intentions to apply. It determined the extent to which participants tended to apply for jobs in the organization they visited through the corporate website. This construct was measured using a six-item scale developed by Lin (2010). A sample item was: "I have a plan to apply for jobs in the organization". The reliability for these data was 0.864 .

3.2.7 Control variable. In addition to the psychological variables discussed above, respondents' demographic information was also taken into consideration for this study. To test the research model, respondents' age, gender and education level were controlled as they were reported to be influential in taking a career-related decision in past studies.

\subsection{Overview of analyses}

Consistent with many past works in this field, the study analyses were conducted through three consecutive steps. That is, first, reliability, validity, multicollinearity and common method bias (CMB) were evaluated using confirmatory factor analysis (CFA); second, as recommended by Hu and Bentler (1999), the data suitability of the measurement model and path model was assessed through established model fit indices such as Chi-square $\left(\chi^{2}\right)$, the ratio of $\chi^{2}$ to the degree of freedom $\left(\chi^{2} / d f\right)$, the root mean square error of approximation (RMSEA), the standardized root mean square residual (SRMR), comparative fit index (CFI), and $p$ of close fit (PCLOSE); and finally, the research hypotheses were tested using structural equation modeling (SEM) with standardized path coefficients. Statistical programs such as SPSS (version 25) and AMOS (version 24) were applied to perform the analyses. To conduct analysis concerning the moderating effects, the interacting variables were first calculated as mean-centered to avoid potential multicollinearity threats for the interacting terms.

\section{Results}

\subsection{Tests of $C M B$, reliability, multicollinearity and validity}

To confirm whether the measurement items were free from the influence of CMB, Harman's single factor test was conducted. The test revealed that a single factor accounted for $34.87 \%$, confirming that the CMB was not a major concern (Podsakoff et al., 2003). To examine the internal consistency of the study construct, Cronbach's alpha $(\alpha)$ values were taken into account. The test results exposed that $\alpha$ values ranged from 0.726 to 0.864 , suggesting the
Recruiting on the net 
construct reliability (shown in Table 1). The tolerance values were more than 0.10 and the variance inflation factors (VIF) did not surpass the criterion of 10, indicating that the study variables were free from multicollinearity (Hair et al., 2009).

The construct validity was evaluated by assessing the convergent validity and discriminant validity. All the average variance extracted (AVE) values for the study variables were above the minimum cut-off point of 0.50 , indicating convergent validity. Figure 2 depicted that the item loadings for the respective construct were well above 0.50, ensuring further support for the convergent validity. Each construct's maximum shared variance (MSV) was found to be lower than its AVE, signifying support for the discriminant validity (Fornell and Larcker, 1981).

\subsection{Test of model fit}

After ensuring the reliability and validity of the study constructs, established fit indices were taken into account to determine the data suitability of the measurement model and path model. Table 2 shows that all the fit indices such as $\chi^{2} / d f$, CFI, SRMR, RMSEA, PCLOSE of the six-factor measurement model fit the data significantly better than the one-factor model, signifying support for the data suitability and indicating further evidence for the discriminant validity (Huang, 2011). Based on the research model, hypothesized relationships among the variables were incorporated to assess the path model using the same set of indices applied to test the measurement model. Table 2 also shows that all the indices fit the data well, and the path model explained $59 \%$ of variance $\left(R^{2}\right)$ in the dependent variable (i.e. intentions to apply for jobs), suggesting a suitable explanatory power of the model.

\subsection{Hypotheses testing}

To test the research hypotheses, SEM with additional 5,000 samples of 95\% bias-corrected confidence intervals (CI) was conducted. Table 3 presents the test results. As predicted, all the hypotheses regarding mediation were supported as follows: corporate reputation was significantly related to application intentions (H1) and website attitudes (H2); perceived ease of use was significantly connected to website attitudes (H3); perceived usefulness was significantly associated with website attitudes (H4) and application intentions (H5); Website attitudes were significantly related to application intentions (H6); as well as the mediating effects of website attitudes on the association of corporate reputation, perceived ease of use and perceived usefulness with application intentions were found to be significant (H7a, H7b and H7c). Noticeably, Website attitudes appeared to be a partial mediator as both the direct and indirect effects of the exogenous variables on the endogenous variable of this study were found to be significant (Baron and Kenny, 1986).

Contrary to the hypothesis, the moderating effect of perceived value fit on the relationship between corporate reputation and application intentions was not significant (represented in Table 3), therefore failing to support hypothesis H8. In regard to hypothesis H9, the moderating effect of perceived value fit on the relationship between perceived usefulness and application intentions was found to be significant, hence supporting the notion that the impact of perceived usefulness on application intentions would be stronger for a low level of perceived value fit while such impact would be weaker for a high level of perceived value fit. Figure 3 depicts the interaction plot to help readers understand the dynamics of moderating effects of perceived value fit on the relationship between perceived usefulness and application intentions.

\section{Discussion}

\subsection{Interpretation of results}

The main purpose of this study was to examine prospective employees' intentions to apply for jobs in an organization by integrating signaling theory and TAM into a single framework, 


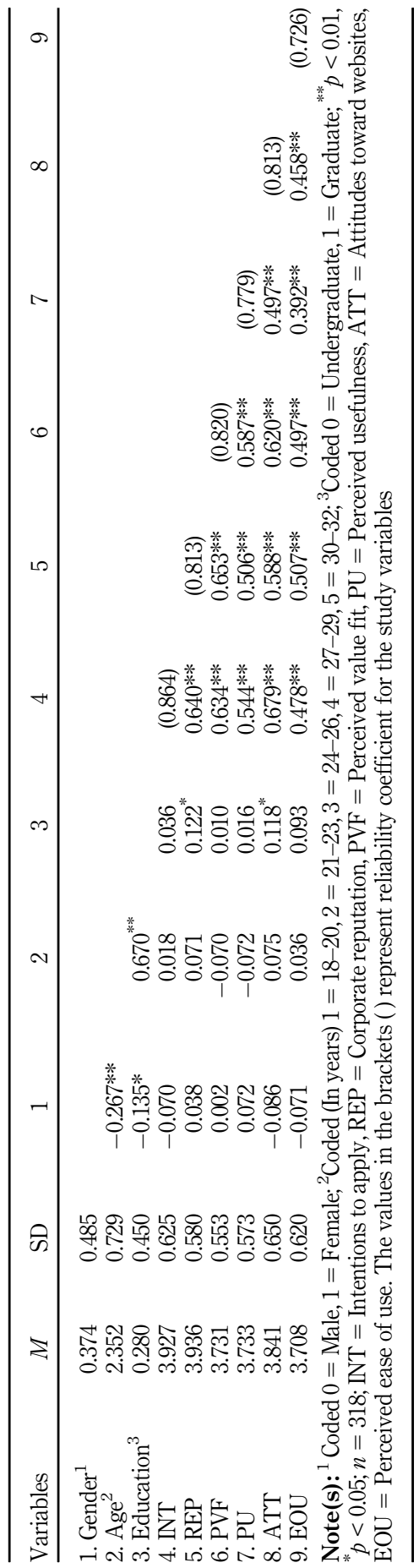

Recruiting on the net

Table 1. Means, standard deviations and correlations among the variables 
PRR

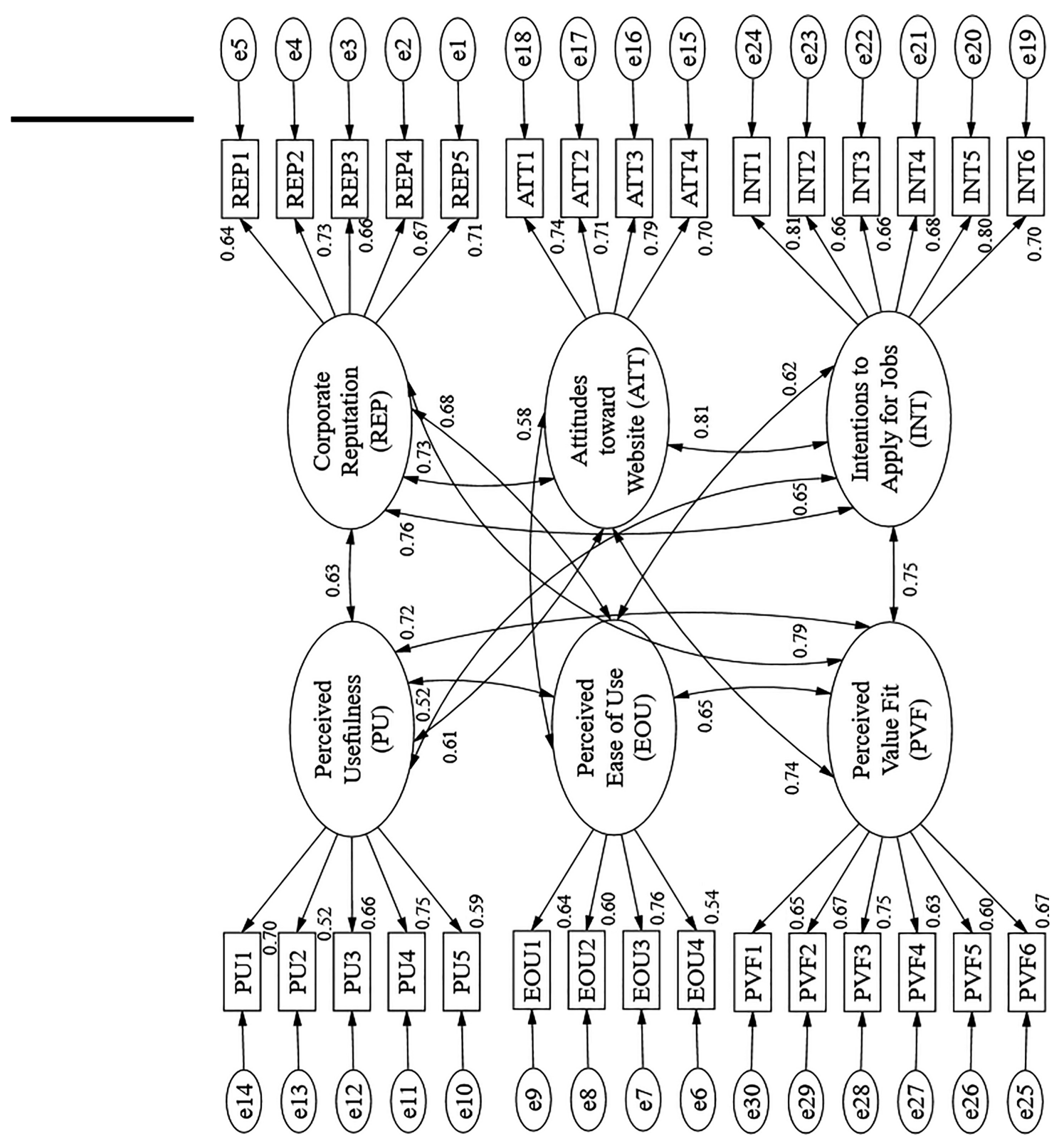

Figure 2.

Measurement model 


\begin{tabular}{lccl}
\hline Model Fit Index & Measurement Model & Path Model & Recommended Value \\
\hline Chi-square $\left(\chi^{2}\right)$ & 792.171 & 13.208 & \\
Degree of freedom $(d f)$ & 390 & 6 & \\
The ratio of $\chi^{2}$ to $d f$ & 2.031 & 2.201 & $\leq 3.0$ (Hu and Bentler, 1999) \\
CFI & 0.903 & 0.994 & $\geq 0.90$ (Hu and Bentler, 1999) \\
SRMR & 0.053 & 0.024 & $<0.10$ (Hu and Bentler, 1999) \\
RMSEA & 0.057 & 0.062 & $<0.80$ (Hu and Bentler, 1999) \\
PCLOSE & 0.022 & 0.286 & $>0.01$ (Hu and Bentler, 1999)
\end{tabular}

Note(s): Fit indices for one-factor measurement model were: $\chi^{2}=1,328.066, d f=405, \chi^{2} / d f=3.279$, $\mathrm{CFI}=0.778, \mathrm{SRMR}=0.068$, RMSEA $=0.085$, PCLOSE $=0.000$, suggesting very poor fit

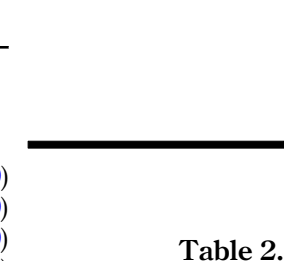

Fit indices of sixfactors measurement model and path model

\begin{tabular}{|c|c|c|c|c|c|c|c|}
\hline $\begin{array}{l}\text { Hypo- } \\
\text { thesis }\end{array}$ & Paths & $\begin{array}{l}\text { Direct } \\
\text { effects }\end{array}$ & $\begin{array}{l}\text { Indirect } \\
\text { effects }\end{array}$ & $\begin{array}{l}\text { Interaction } \\
\text { effects }\end{array}$ & $\begin{array}{c}p- \\
\text { value }\end{array}$ & $\begin{array}{c}\text { 95\% CI [Low, } \\
\text { High] }\end{array}$ & $\begin{array}{l}\text { Hypothesis } \\
\text { supported } \\
\text { (Yes/No) }\end{array}$ \\
\hline H1 & $\mathrm{REP} \rightarrow \mathrm{INT}$ & 0.331 & & & 0.001 & & Yes \\
\hline $\mathrm{H} 2$ & $\mathrm{REP} \rightarrow \mathrm{ATT}$ & 0.380 & & & 0.001 & & Yes \\
\hline $\mathrm{H} 3$ & $\mathrm{EOU} \rightarrow \mathrm{ATT}$ & 0.172 & & & 0.001 & & Yes \\
\hline $\mathrm{H} 4$ & $\mathrm{PU} \rightarrow \mathrm{ATT}$ & 0.237 & & & 0.001 & & Yes \\
\hline H5 & $\mathrm{PU} \rightarrow \mathrm{INT}$ & 0.163 & & & 0.001 & & Yes \\
\hline $\mathrm{H} 6$ & $\mathrm{ATT} \rightarrow \mathrm{INT}$ & 0.391 & & & 0.001 & & Yes \\
\hline H7a & $\mathrm{REP} \rightarrow \mathrm{ATT} \rightarrow \mathrm{INT}$ & & 0.149 & & 0.001 & & Yes \\
\hline $\mathrm{H} 7 \mathrm{~b}$ & $\mathrm{EOU} \rightarrow \mathrm{ATT} \rightarrow \mathrm{INT}$ & & 0.067 & & 0.018 & & Yes \\
\hline $\mathrm{H} 7 \mathrm{c}$ & $\mathrm{PU} \rightarrow \mathrm{ATT} \rightarrow \mathrm{INT}$ & & 0.093 & & 0.001 & & Yes \\
\hline $\mathrm{H} 8$ & $\mathrm{PVF} \times \mathrm{REP} \rightarrow \mathrm{INT}$ & & & 0.062 & 0.233 & {$[-0.163,0.040]$} & No \\
\hline H9 & $\mathrm{PVF} \times \mathrm{PU} \rightarrow \mathrm{INT}$ & & & -0.119 & 0.024 & {$[-0.221,-0.016]$} & Yes \\
\hline
\end{tabular}
Model 1 was applied

Table 3.

Summary results for hypotheses testing

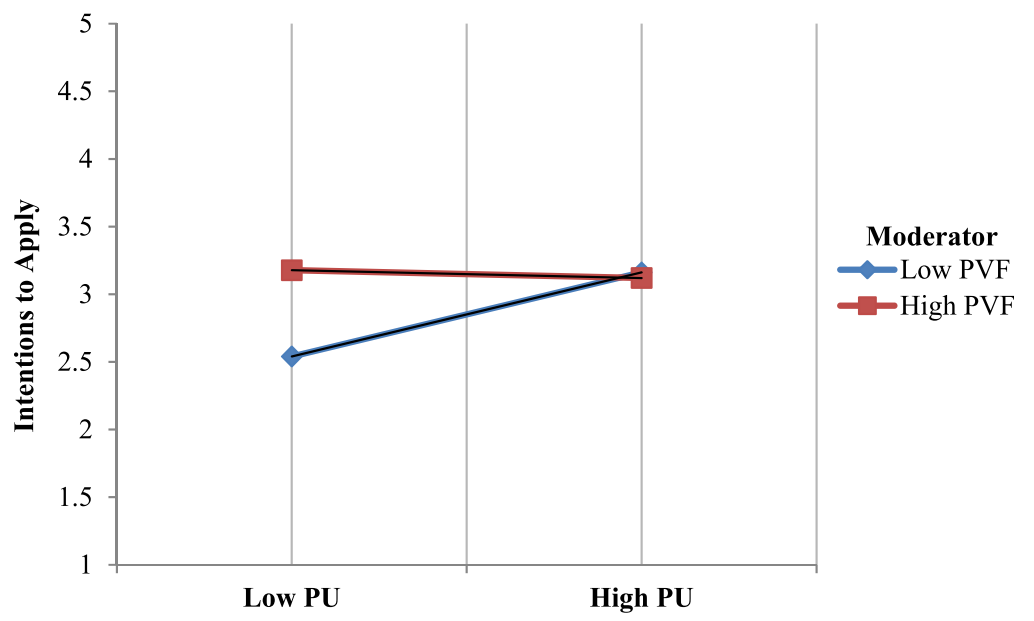

Figure 3.

Moderating effects of perceived value fit (PVF) 
with a particular emphasis on the mediating processes of website attitudes and underlying conditions of perceived value fit on the hypothesized linkages within the research model. In line with many previous studies in this field, all the direct and mediating hypotheses were supported, as suggested by the study findings.

However, it is worth mentioning that the construct "attitudes towards websites" appeared to be a partial, rather than a full, mediator in this study, as suggested by Baron and Kenny (1986). It is due to the fact that all the coefficients $(\beta)$ of direct and indirect paths from the independent variables (i.e. perceived corporate reputation and perceived usefulness) to the dependent variables (i.e. job seekers' intentions to apply for jobs in an organization) were found to be significant in the research model.

As per the hypothesis, the study results also revealed that perceived value fit negatively moderates the relationship between perceived usefulness and intentions to apply for jobs in an organization. More specifically, the impact of perceived usefulness on intentions to apply becomes stronger for job seekers with a low level of perceived value fit, while such impact becomes weaker for job seekers with a high level of value fit perceptions, suggesting its dynamic conditional roles in the predicted relationship.

Contrary to the hypothesis, perceived value fit could not moderate the relationship between corporate reputation and intentions to apply for jobs in an organization, implying that the impact of reputation on applicant attraction is not conditional on the perceived value fit. One compelling reason for such type of findings may be due to the number of items used for perceived value fit in this study. That is, the measuring items utilized for perceived value fit might produce reduced variability in predicting results.

\subsection{Theoretical contribution}

As discussed earlier, empirical research regarding the linkage between a firm's website and applicants' attraction is not copious. This study is likely to complement and extend prior research in three ways. First, to the best of knowledge, no research in this field, to date, examined the conditional roles of perceived value fit in the suggested relationships, responding to a call from early researchers (Lin, 2010; Tso et al., 2010). Hence, the findings of the study would add value to the existing literature in this field.

Second, while previous studies on this domain individually demonstrated the roles of variables considered in our theoretical model, this study is the first to utilize the signaling theory and the TAM simultaneously in a single framework to investigate how prospective job applicants' attraction occurs before their joining in a potential hiring organization, representing a complex nature of associations among the study variables.

Third, while many scholars (Hossain et al., 2019a, b; e.g. Hossain et al., 2020) in their studies argued that perceived ease of use and perceived usefulness are the major antecedents of behavioral intentions, the present study findings revealed that the impact of those antecedents on behavioral intentions can be mediated through individuals' attitudes toward the technology, suggesting another contribution to the existing body of knowledge in the TAM literature.

Fourth, while past studies were mostly centered on the Western contexts, depending on fictitious company websites for measuring respondents' attitudes and application intentions, adequate empirical research for the application attraction process in the Asian context is still unavailable, even less so in the context of Bangladesh. Therefore, this study, using respondents' actual visited company websites in a developing country context, is likely to be an important step forward for examining its generalizability in a broader context.

\subsection{Managerial implications}

This study also offers some important practical implications for HR managers in today's competing firms. First, in order to enjoy an edge over competitors, HR practitioners need to 
boost prospective candidates' attraction to their firms as they are the main key sources for organizational performances in any respect. Along with the traditional recruitment campaign, firms need to develop their corporate website in such a way so that prospective employees find it user friendly and useful for all kinds of their queries concerning the job and organizational information, which in turn affect their attitudes toward the corporate website that consequently result in higher application intentions, as suggested by the study findings.

Second, a hiring firm can also consider its corporate website as a source to promote its reputation status to potential job candidates. The study results showed that the corporate reputation-application intentions link was not influenced by the level of job seekers' perceived value fit in this direction, indicating its robust role in predicting applicants' intentions to apply for jobs in a firm. Therefore, it is recommended that HR managers consider their corporate websites as well as other social media platforms (such as Facebook, Twitter, YouTube, Instagram, etc.) to uphold corporate reputations due to the fact that millennial job seekers appear to be more attached to such platforms.

Third, millennial job seekers are more individualistic and narcissistic in nature (Twenge, 2009), indicating that they value their personal norms and interests over anything. The study results revealed that the relationship between perceived usefulness and application intentions is conditional on the level of job seekers' value fit perceptions. That is, whether the perceived usefulness-application intentions link will be stronger or weaker, it is conditional on the perceived value fit. Therefore, it is suggested that, in any respect, organizations should disclose relevant information about their work environments so that potential employees may assess their value fit.

\subsection{Limitations and future research directions}

No study is without its limitations. This study should be interpreted with some drawbacks. First, the research design was entirely based on the cross-sectional data collected from undergraduate and graduate students within a single country at a single point of time, thereby raising concerns about the causality of the study variables (Podsakoff $e$ t al., 2012). Hence, in order to obtain more robust results fit for generalization, future research should undertake a longitudinal study targeting genuine job seekers from diverse cultures.

Second, this study considered applicants' perceived value fit as a single dimension scale. Few researchers in this area of the study demonstrated this construct as two-dimensional scales such as person-organization (P-O) fit and person-job (P-J) fit. Therefore, future researchers in this discipline can address this phenomenon in their studies to examine the more specific influence of job seekers' perceived value fit on the relationships investigated in the research model for this study.

Finally, although this study incorporated the signaling theory and the TAM in a single framework, it considered applicants' intentions to apply as the ultimate outcome of the independent variables. Sheeran and Webb (2016) noted that individuals often do not do the things what they intend to do, indicating another limitation of the present study. Therefore, future studies should consider job seekers' actual behavioral construct to address this theoretical issue and yield vigorous findings.

\section{References}

Ahmad, S., Mat Tahar, R.B., Cheng, J.K. and Yao, L. (2017), "Public acceptance of residential solar photovoltaic technology in Malaysia”, PSU Research Review, Vol. 1 No. 3, pp. 242-254.

Banerjee, P. and Gupta, R. (2019), "Talent attraction through online recruitment websites: application of web 2.0 technologies", Australasian Journal of Information Systems, Vol. 23, doi: 10.3127/ajis. v23i0.1762. 
Baron, R.M. and Kenny, D.A. (1986), "The moderator-mediator variable distinction in social psychological research: conceptual, strategic, and statistical considerations", Journal of Personality and Social Psychology, Vol. 51 No. 6, pp. 1173-1182.

Bednarska, M.A. (2016), "Complementary person-environment fit as a predictor of job pursuit intentions in the service industry", Contemporary Economics, Vol. 10 No. 1, pp. 27-38.

Cable, D.M. and DeRue, D.S. (2002), "The convergent and discriminant validity of subjective fit perceptions", Journal of Applied Psychology, Vol. 87 No. 5, pp. 875-884.

Cable, D.M. and Turban, D.B. (2001), "Establishing the dimensions, sources and value of job seekers' employer knowledge during recruitment", Research in Personnel and Human Resources Management, Vol. 20, pp. 115-163.

Chaudhary, R. (2018), "Can green human resource management attract young talent? An empirical analysis", Evidence-Based HRM, Vol. 6 No. 3, pp. 305-319.

Chowdhury, M.S. and Kang, D. (2021), "Modeling corporate environmental responsibility perceptions and job-seeking intentions: examining the underlying mechanism”, Sustainability, Vol. 13 No. 11, p. 6270.

Chowdhury, M.S., Yun, J. and Kang, D. (2021), "Towards sustainable corporate attraction: the mediating and moderating mechanism of person-organization fit", Sustainability, Vol. 13 No. 21, pp. 1-14.

Cober, R.T., Brown, D.J., Levy, P.E., Cober, A.B. and Keeping, L.M. (2003), "Organizational web sites: web site content and style as determinants of organizational attraction”, International Journal of Selection and Assessment, Vol. 11 Nos 2-3, pp. 158-169.

Davis, F.D. (1989), "Perceived usefulness, perceived ease of use, and user acceptance of information technology", MIS Quarterly, Vol. 13 No. 3, p. 319.

Dineen, B.R., Ash, S.R. and Noe, R.A. (2002), “A web of applicant attraction: person-organization fit in the context of web-based recruitment", Journal of Applied Psychology, Vol. 87 No. 4, pp. 723-734.

Ehrhart, K.H., Mayer, D.M. and Ziegert, J.C. (2012), "Web-based recruitment in the Millennial generation: work-life balance, website usability, and organizational attraction”, European Journal of Work and Organizational Psychology, Vol. 21 No. 6, pp. 850-874.

Fishbein, M. and Ajzen, I. (1975), Belief, Attitude, Intention, and Behavior: an Introduction to Theory and Research, Addison-Wesley, MA.

Fishbein, M., Hennessy, M., Yzer, M. and Douglas, J. (2003), "Can we explain why some people do and some people do not act on their intentions?", Psychology, Health and Medicine, Vol. 8, pp. 3-18.

Fornell, C. and Larcker, D.F. (1981), "Evaluating structural equation models with unobservable variables and measurement error", Journal of Marketing Research, Vol. 18 No. 1, pp. 39-50.

Gregory, C.K., Meade, A.W. and Thompson, L.F. (2013), "Understanding internet recruitment via signaling theory and the elaboration likelihood model", Computers in Human Behavior, Elsevier, Vol. 29 No. 5, pp. 1949-1959.

Griepentrog, B.K., Harold, C.M., Holtz, B.C., Klimoski, R.J. and Marsh, S.M. (2012), "Integrating social identity and the theory of planned behavior: predicting withdrawal from an organizational recruitment process", Personnel Psychology, Vol. 65 No. 4, pp. 723-753.

Hair, J.F., Black, W.C., Babin, B.J. and Anderson, R.E. (2009), Multivariate Data Analysis, Prentice-Hall, Upper Saddle River.

Highhouse, S., Lievens, F. and Sinar, E.F. (2003), "Measuring attraction to organizations", Educational and Psychological Measurement, Vol. 63 No. 6, pp. 986-1001.

Hossain, S.F.A., Nurunnabi, M., Hussain, K. and Saha, S.K. (2019a), "Effects of variety-seeking intention by mobile phone usage on university students' academic performance”, Cogent Education, Vol. 6 No. 1, doi: 10.1080/2331186X.2019.1574692. 
Hossain, S.F.A., Xi, Z., Nurunnabi, M. and Anwar, B. (2019b), "Sustainable academic performance in higher education: a mixed method approach", Interactive Learning Environments, pp. 1-14, doi: 10.1080/10494820.2019.1680392.

Hossain, S.F.A., Nurunnabi, M., Hussain, K. and Shan, X. (2020), "Smartphone-based m-shopping behavior and innovative entrepreneurial tendency among women in emerging Asia", International Journal of Gender and Entrepreneurship, Vol. 12 No. 2, pp. 173-189.

Hu, L.T. and Bentler, P.M. (1999), "Cutoff criteria for fit indexes in covariance structure analysis: conventional criteria versus new alternatives", Structural Equation Modeling, Vol. 6 No. 1, pp. 1-55.

Huang, J.T. (2011), "Application of planned behavior theory to account for college students' occupational intentions in contingent employment", Career Development Quarterly, Vol. 59 No. 5, pp. 455-466.

Kallgren, C.A., Reno, R.R. and Cialdini, R.B. (2000), "A focus theory of normative conduct: when norms do and do not affect behavior", Personality and Social Psychology Bulletin, Vol. 26 No. 8, pp. 1002-1012.

Lin, H.F. (2010), "Applicability of the extended theory of planned behavior in predicting job seeker intentions to use job-search websites", International Journal of Selection and Assessment, Vol. 18 No. 1, pp. 64-74.

Massaro, D.W., Petty, R.E. and Cacioppo, J.T. (1988), "Communication and persuasion: central and peripheral routes to attitude change", The American Journal of Psychology, Vol. 101 No. 1, p. 155.

Melo, T. and Garrido-Morgado, A. (2012), "Corporate reputation: a combination of social responsibility and industry", Corporate Social Responsibility and Environmental Management, Vol. 19 No. 1, pp. 11-31.

Palmer, J.W. (2002), "Website usability, design, and performance metrics", Information Systems Research, Vol. 13 No. 2, pp. 151-167.

Pfieffelmann, B., Wagner, S.H. and Libkuman, T. (2010), "Recruiting on corporate web sites: perceptions of fit and attraction", International Journal of Selection and Assessment, Vol. 18 No. 1, pp. 40-47.

Podsakoff, P.M., MacKenzie, S.B., Lee, J.Y. and Podsakoff, N.P. (2003), "Common method biases in behavioral research: a critical review of the literature and recommended remedies", Journal of Applied Psychology, Vol. 88 No. 5, pp. 879-903.

Podsakoff, P.M., MacKenzie, S.B. and Podsakoff, N.P. (2012), "Sources of method bias in social science research and recommendations on how to control it", Annual Review of Psychology, Vol. 63 No. 1, pp. 539-569.

Safari, K., Bisimwa, A. and Buzera Armel, M. (2020), "Attitudes and intentions toward internet banking in an under developed financial sector", PSU Research Review, Vol. ahead-of-print, doi: 10.1108/PRR-03-2020-0009.

Saks, A.M. and Ashforth, B.E. (1997), "A longitudinal investigation of the relationships between job information sources, applicant perceptions of fit, and work outcomes”, Personnel Psychology, Vol. 50 No. 2, pp. 395-426.

Sheeran, P. and Webb, T.L. (2016), "The intention - behavior gap", Social and Personality Psychology Compass, Vol. 10 No. 9, pp. 503-518.

Shin, I., Hur, W.M. and Kang, S. (2016), "Employees' perceptions of corporate social responsibility and job performance: a sequential mediation model”, Sustainability, Vol. 8 No. 5, pp. 1-12.

Spence, M. (1973), “Job market signaling”, Quarterly Journal of Economics, Vol. 87, pp. 355-374.

Story, J., Castanheira, F. and Hartig, S. (2016), "Corporate social responsibility and organizational attractiveness: implications for talent management”, Social Responsibility Journal, Vol. 12 No. 3, pp. 484-505. 
Tsai, Y.H., Lin, C.P., Ma, H.C. and Wang, R.T. (2015), "Modeling corporate social performance and job pursuit intention: forecasting the job change of professionals in technology industry", Technological Forecasting and Social Change, Vol. 99, pp. 14-21.

Tso, G.K.F., Yau, K.K.W. and Cheung, M.S.M. (2010), "Latent constructs determining Internet job search behaviors: motivation, opportunity and job change intention", Computers in Human Behavior, Vol. 26 No. 2, pp. 122-131.

Twenge, J.M. (2009), "Generational changes and their impact in the classroom: teaching generation Me", Medical Education, Vol. 43 No. 5, pp. 398-405.

Uggerslev, K.L., Fassina, N.E. and Kraichy, D. (2012), "Recruiting through the stages: a meta-analytic test of predictors of applicant attraction at different stages of the recruiting process", Personnel Psychology, Vol. 65 No. 3, pp. 597-660.

Waples, C.J. and Brachle, B.J. (2020), "Recruiting millennials: exploring the impact of CSR involvement and pay signaling on organizational attractiveness", Corporate Social Responsibility and Environmental Management, Vol. 27 No. 2, pp. 870-880.

Yeum, A. and Han, E. (2014), "A study on relations between corporate citizenship, corporate reputation and job pursuit intention with an emphasis on applying the theory of reasoned action”, The Korean Journal of Advertising and Public Relations, Vol. 16 No. 4, pp. 77-108.

Zhang, Q., Cao, M., Zhang, F., Liu, J. and Li, X. (2020), "Effects of corporate social responsibility on customer satisfaction and organizational attractiveness: a signaling perspective", Business Ethics, Vol. 29 No. 1, pp. 20-34.

\section{Corresponding author}

Md Sohel Chowdhury can be contacted at: sohel@inha.edu

For instructions on how to order reprints of this article, please visit our website:

www.emeraldgrouppublishing.com/licensing/reprints.htm

Or contact us for further details: permissions@emeraldinsight.com 